\title{
The Three Characteristics of an Effective Teacher
}

\author{
Elock Emvula Shikalepo \\ Namibia University of Science and Technology, Namibia
}

\begin{abstract}
This study endeavoured to establish the characteristics of effective teachers and how these characteristics assisted teachers to improve learner performance. To address this aim, a case study design was employed as a methodology for the study, consisting of five rural schools. A literature study was conducted, alongside semi-structured individual interviews with five school principals and focus group interviews with twenty eight teachers from the same rural schools from where school principals were drawn. The collected data was analysed thematically, by establishing themes and their emerging categories. The established themes and their categories were interpreted and discussed to answer the research questions. The major findings of the study revealed that an effective teacher has a blend of three characteristics, namely, professional characteristics, personality characteristics and social characteristics. The blend of characteristics contribute to the quality of teaching and learning processes. The study recommended that educational practitioners in diversity should be cognisant of the characteristics of effective teachers and nurture them appropriately as these characteristics have a life-transforming effects on the lives of the learners.
\end{abstract}

Keywords: Good teacher; Effective teacher; Teaching; Learning; Characteristics; Professional characteristics; Personal characteristics; Social characteristics; Optimal learning.

(c) (1) CC BY: Creative Commons Attribution License 4.0

\section{Introduction}

Competent and qualified teachers are essential for effective teaching and for enhancing the quality of learning. The capabilities of a competent teacher as demonstrated in classrooms play a vital role in provoking efficient and effective learning on the part of the learners (Markley, 2004). Researchers emphasise that teachers have a fundamental role in their learners' academic achievement and their quality can highly influence learners' performance outcomes (Campbell et al., 2004; Lasley et al., 2006; Rockoff, 2004).

An effective teacher encompasses a range of skills, competencies and motivation to execute good teaching. Specific characteristics are required in order to expect effective teaching that translate into optimal learning (Adedeji and Olaniyan, 2011). There has been increasing attention and debates in literature on teacher quality and effectiveness relating to the mastery of learning outcomes by learners (Barley and Beesley, 2007; Rivkin et al., 2005; Rockoff, 2004). Researchers are in agreement that competent and qualified teachers are essential for efficient functioning of educational systems and for enhancing the quality of learning (Shishavan, 2009). Effective teachers are therefore critical in ensuring that optimal learning takes place in classrooms.

Even though it has been established that teachers play a fundamental role in their learners' academic achievement as their quality can determine the extent to which learners are likely to master their learning outcomes (Lasley et al., 2006; Rockoff, 2004; Shishavan, 2009), there is lack of evidence and awareness about what constitutes a good teacher since some teachers are more productive than others in promoting learner achievement, despite all of them being called teachers.

Understanding the characteristics that distinguish effective teachers from ineffective teachers is significant in ensuring an increased number of good teachers in schools in order to improve the quality of education (Maurer, 2012). Without precise knowledge of what makes a good teacher, education authorities will continue to encounter persisting difficulties in tracing, recruiting and retaining teachers who are truly meant to be teachers (Maurer, 2012).

Some of the characteristics that were traditionally deemed as the sole criteria for selecting good teachers are no longer applicable to modern times, as such criteria alone do not result in increased optimal learning (Rivkin et al., 2005). Characteristics such as professional qualifications and years of experience may sound relevant as requirements for a teaching career, but such requirements alone cannot define a good teacher, nor predict improved learner performance (Maurer, 2012; Rivkin et al., 2005). Moreover, it is also difficult to identify and define good teachers because they are not the same individual year after year in terms of the quality of teaching and learner performance output (Maurer, 2012).

Various scholars have attempted to define an effective teacher. Walker (2008), relates the concept of 'good teacher' to 'effective teacher' as a particular kind of teacher who is most successful in helping learners to learn. 'Effective teachers' and 'good teachers' are therefore concepts that can be used synonymous as they both represent teachers who have the diverse abilities to help learners master learning outcomes. Walker (2008), emphasis on 'most successful' teacher to engender learning goes beyond the remarks by Maurer (2012), on the length of time it takes to identify a good teacher. While Maurer (2012), stresses that good teachers may not be the same year after year, Walker (2008), contradicts Maurer (2012), view in the sense that to be 'most successful', indicates length of time, 
implying that good teachers remain the same year after year. Teachers' identification as being effective is based on the characteristics they are manifesting consistently.

Walker (2008), describes 'characteristics' as teachers' special qualities that enable them to achieve success in their teaching responsibilities. As teacher characteristics are considered the factors underlying learners' performance, a good teacher represents that person who demonstrates the necessary characteristics that enable learners to master the learning outcomes which translates into optimal learning (Maurer, 2012; Sharma and Gupta, 2014). As optimal learning is closely related to effective teachers, it is important to understand what constitute a good teacher in order to establish the appropriateness of a person suited for the teaching profession.

Arnon and Reichel (2007), postulates that a good teacher is synonymous with an 'ideal teacher' and can be defined by characteristics that facilitate good teaching. Moreover, Adedeji and Olaniyan (2011), concurring with Maurer (2012), stress that good teaching refers to teachers being able to facilitate good instruction that leads to effective learning, which in turn leads to thorough and lasting acquisition of knowledge and skills. In the context of this study, the thorough and lasting acquisition of knowledge and skills is what is referred to as optimal learning. Many studies determined the character, competencies and behaviour of a good teacher (Devine et al., 2013; Dewar, 2002; Okoro and Chukwudi, 2011). This determination of characters, competencies and behaviour of a good teacher as found in literature, coupled with empirical evidence from the participants, formed the backbone of this study.

\section{Statement of the Problem}

Competent and qualified teachers are essential for effective teaching and for enhancing the quality of learning. The capabilities of a competent teacher as demonstrated in the classroom play a vital role in provoking effective and efficient learning on the part of the learners (Markley, 2004). Teachers have a fundamental role in their learners' academic achievement and their quality can highly influence learners' performance outcomes. Even though it has been established that teachers play a fundamental role in their learners' academic achievement as their quality can determine the extent to which learners are likely to master their learning outcomes (Lasley et al., 2006; Rockoff, 2004; Shishavan, 2009), there is lack of evidence and awareness about what constitutes a good teacher since some teachers are more productive than others in promoting learner achievement. In addressing this gap, this study endeavoured to establish the characteristics of a good teacher and how these characteristics assist teachers to improve learner performance in schools.

\section{Methodology}

The methodology employed for this study is described according to the following layout.

\subsection{Research Design}

The purpose of this study was to establish the characteristics of a good teacher and how these characteristics assist teachers to improve learner performance in schools. In executing this purpose, a qualitative case study design was conducted. A case study allows an exploration from multiple perspectives of the complexity and uniqueness of a particular project or programme functioning in a real-life context, and provide specific and contextually rich data (Simons, 2009). An explanatory case study design was relevant to this study, to enable the researcher to ask the characteristics of effective teachers from participants' perspectives in their own environment and allow participants to explain why they think those characteristics matters and how such characteristics assist teachers to teach better for learners to learn better.

\subsection{Sampling and Participants}

Participants consisted of five school principals, two education officials and twenty eight teachers. Participants were sampled from two education offices and five rural schools of Omusati region, Namibia. Participants were sampled using non-probability sampling techniques. In non-probability sampling, the researcher has no way of forecasting or guaranteeing that each member of the population will be represented in the sample and some members of the population have little or no chance of being sampled (Leedy and Omrod, 2005). In non-probability sampling, the researcher has the prerogative to judge the population and produce the sample. School principal participants were sampled by means of purposive sampling. Purposive sampling involves researchers handpicking the participants to be included in the sample on the basis of the researcher's judgments of participants' typicality to the phenomenon of study (Chiromo, 2009). As principals were in charge of schools as learning institution in rural areas, they were better positioned to articulate rural-based issues and how they influenced teaching and learning activities at their schools.

Teacher participants and two education officials were sampled using snowball sampling. Snowball sampling is a type of non-probability sampling technique where the sampled members indicate other members who could provide rich information for the study (Chiromo, 2009). School principals and education officials assisted the researcher in getting hold of long-serving teachers and education officials in the region. Long-serving teachers in the teaching fraternity in a rural setting were well-positioned to outline the conditions that compromised successful teaching and learning in rural areas. Similarly, long-serving education officials who discharge education administration and management in Omusati region, could equally contribute meaningful insights to the research intentions. 


\subsection{Data Collection Methods}

Data was collected by means of a literature study and an empirical investigation. The researcher reviewed existing literature pertaining effective teachings and good teachers. To complement the data from the literature study, an empirical investigation was commissioned, which used individual and focus group interviews. Individual interviews were conducted with school principals, on a voluntary basis, at their respective schools, as well as with two education officials at their respective offices.

Semi-structured focus group interviews were conducted with teachers at their respective schools, in a focus group of six teachers. The semi-structured nature of the interviews allowed the researcher to generate a considerable amount of data about the participants' collective opinions and experiences with regard qualities and characteristics of a good teacher. Focus group participation was voluntary, and all members of the focus group and other participants were given background information about the study.

As focus group interviewing explores the views of diverse groups of people, the researcher was able to unpack different perspectives within the group in relation to the topic of discussion (Choy, 2014). In addition, asking a group of people to respond jointly to common questions can yield varied and detailed data on the same topic (Dudwick et $a l .$, 2006). The questions for both the individual and focus group interviews were open-ended questions in order to provide opportunities for both the researcher and participants to discuss certain topics in more detail. The openended nature of the questions provided opportunities for the participants to provide as much information as possible regarding the characteristics of effective teachers and for the researcher to prompt participants for a deeper understanding.

\subsection{Data Analysis}

The data was analysed according to the themes and patterns which emerged as a result of a process of inductive categorisation (Atieno, 2009; Johnson and Onwuegbuzie, 2004). The findings were interpreted and discussed in relation to the existing literature findings. The interpretation and discussion also made use of the verbatim excerpts from the interview data because they carry authenticity and weight of the research findings.

\section{Trustworthiness of Findings}

The trustworthiness of the research findings were established by triangulation and member checking.

\subsection{Triangulation}

Triangulation is the use of multiple methods to data collection in order to enable these methods to complement each other and to confirm that the data present common codes and themes (Creswell, 2014; Kahn and Best, 2006; Leedy and Omrod, 2005). According to Guba (1981), the use of different methods in a study compensates for their individual limitations and exploits their respective benefits. This study employed data triangulation as one of the types of triangulation.

Data triangulation involves using different sources of information to increase the trustworthiness of the study findings (Creswell, 2014). Triangulation involves using different sources of research instruments, such as interviews, focus group discussions or participant observation that utilises different informants to enhance the quality of the data from different sources (Anney, 2014). The researcher has used different data collection methods in this study, which included individual interviews with school principals and education officials, as well as focus group interviews with teacher participants. These multiple methods all produced data that complemented each other in addressing the research goals. The similarities in responses of the informants represents the authenticity of the research findings.

\subsection{Member Checking}

Member checking seeks to establish whether the participants agree with what the researcher have written about the data they provided during the inquiry (Ary et al., 2010). Member checks requires that the data interpretations and discussions as they are derived are continuously tested with participants from whom the data was solicited (Guba, 1981).

The aim is for researcher to solicit feedback and share his or her interpretations of the data with the participants to help clear up miscommunication, identify inaccuracies and help obtain additional useful data. For this study, the researcher went back to the participants and shared the interpretation and discussion of the findings with them. This was meant to establish common grounds on the data analysis and interpretation with participants. This iterative process ensured that the findings that were presented were indeed a true and genuine reflection of the original data collected from the participants.

\section{Findings and Discussion}

After the data was analysed thematically, the following characteristics of effective teachers were established, interpreted and discussed.

\subsection{Professional Characteristics}

This characterisation of a good teacher is based on teachers' professional requirements and suitability to serve and fulfil the tasks of the teaching profession. There has been an increasing international debate on teacher quality 
and effectiveness which prompts questions against teachers' suitability in the profession (Devine et al., 2013; Heeralal, 2014; Mitra et al., 2008).

A professional teacher has been described from different perspective by different authors all pointing to having professional skills, knowledge and experience applicable to the teaching profession (Bullock, 2015). Professional knowledge relates to the 'pedagogical content knowledge' which is defined as a teacher's understandings of the concepts being taught and skills needed to contextualise, situate and personalise the content to the learners (Mullock, 2003; Thompson et al., 2004).

Good teachers need to be well conversant with teaching pedagogies as all endeavours aimed at educational development and provision rely much on the competencies that quality teachers express which relate to sound pedagogical skills, knowledge and characteristics (Burnett and Lingam, 2007). Being competent with pedagogic content knowledge implies that good teachers know how to organise and teach learners in a way that learners can demonstrate mastery of the learning content.

The significance of pedagogic content knowledge is consistent with the findings of a study conducted in Australia, where learners rated ability to explain well and engagement in lesson content as an important characteristics of good teaching (White, 2009). Learners also highlighted the importance of classroom management, learner-teacher relationships and listening to learners' input as typical characteristics of a good teacher (Cook-Sather, 2002).

Good teachers do not only impart the already compiled subject curricula, but they go beyond by knowing how their learners learn, understand why their learners learn and how best they can help learners to learn better. Based on this view, a good teacher is described as someone who is able to organise classroom environments for easy management and present unambiguous instructions to learners so they capture the essence of teaching (Bullock, 2015; Murphy et al., 2004). Therefore, a good teacher knows the techniques for creating an orderly and conducive learning environment and presents clear explanations of the subject contents to the learners.

A good teacher presents learning material in an organised and engaging way and uses creative teaching approaches (Duarte, 2013; Samples and Copeland, 2013; White, 2009). Organised teaching materials make it easy for learners to interact with the learning materials and this helps to facilitate the learning and teaching process. To be acquainted with such pedagogic capabilities, good teachers should have undergone an intensive professional training, during the course of which they should have gained intensive professional experience, skills and understanding of what methodologies and pedagogies to apply in their classrooms.

Research on professional teacher behaviours and conduct reveals that good teachers are organised and conduct themselves in a professional manner, are efficient in performing tasks allocated to them, are accountable for the results of their actions and are intelligent in solving problems which draw appreciation from all those who work with them (Vlad and Ciascai, 2014). Professional traits as demonstrated by teachers in behaviours and duty execution are keys in the characterisation of a good teacher.

Despite the challenging nature of the teaching profession, good teachers have the ability to apply the skills and knowledge they have learned during their training into their teaching practice (Bullock, 2015). Good teachers are not only those who are teachers by virtue of merely having a professional qualification, but those with the ability to apply the learned and experienced competencies in their classes and the environment in which they function. A good teacher knows how to adapt to a challenging environment and practice the duties without compromising on output, such as decreased learner achievement. This adaptation was testified by one participant that teachers possess the ability to make an environmental analysis in order to establish their adaptation pattern in the environment they function.

In terms of subject content delivery, a good teacher delivers the subject content in a manner that is very clear, shows knowledge of the subject content, has clear articulation and is able to motivate learners and summarise the main points at the end of the lesson (Duarte, 2013). Learners get the content from a good teacher without misinterpretation of facts, as the teacher imparts subject knowledge in certain terms. Summarising helps learners to get the main points of the lesson without having to struggle with what they have learned during the lesson. Samples and Copeland (2013), point out that one of the ways in which teachers can earn themselves trust from learners is the ability to deliver the subject content effectively to the learners. Trust is essential in motivating learners to seek support from teachers so that learners understand content logically, coherently and explicitly.

With reference to management and leadership, a good teacher knows what style of leadership to use under different circumstances and avoids being arrogant or authoritative (Vlad and Ciascai, 2014). Teachers deal with learners of different characteristics and attitudes. As a result, a good teacher knows what style of leadership to use as determined by the situation and the ability to cope with people of different backgrounds and the required degree of preparedness to counter challenges as may arise. This implies that good teachers do not apply the principle of 'one style fits all' as they understand the nature of their profession and the fact that each learner is unique.

Good teachers are fair at all times, handle learners fairly in terms of teaching, assessment and grading, as well as afford all learners equal privileges and opportunities to make contributions during teaching and learning (Inan, 2014; Khojastehmehr and Takrimi, 2009). Walker (2008), emphasises that good teachers have the understanding that 'fair' does not necessarily mean treating every learner the same but means giving every learner an opportunity to succeed. This reveals that a good teacher understand that not all learners learn in the same way and at the same rate, which require a teacher to use different teaching styles in order to accommodate all learners in their classrooms. Good teachers understand learners' learning styles, and are thus knowledgeable with all the teaching methods applicable to their subjects as well as the different learning styles relevant to their learners (Samples and Copeland, 2013). 
In terms of subject specialisation, a good teacher is well informed with the subject specialisation, they know how to stimulate learners' attention to remain focused on the subject and show determination in their lesson presentation (Espina, 2013; Samples and Copeland, 2013). Because good teachers are well conversant with the subject knowledge in terms of content and delivery, good teachers are open for questioning by learners. This characterisation of teachers helps to ensure mastery of the subject content by learners and instil a sense of pride, trust and motivation among learners to succeed in their learning. Since learners perceive good teachers to impact their motivation to learn, a good teacher connects well with each learner to foster passion and excitement towards a subject (Littkey, 2004).

Learners have described good teachers as individuals who are competent instructors, focusing on the transfer of knowledge and skills in such a way that learners understand what is facilitated (Bullock, 2015; Duarte, 2013; Vlad and Ciascai, 2014). This assertion is consistent with Adeosun et al. (2013), emphasis that only teachers who possess the necessary technical competence and professional skills through a well-coordinated teacher training programme can rise to meet the challenges in the classrooms.

The definition of a good teacher has been contested by some authors. Komarraju (2013), contradicts that what learners classify as a good teacher may not lead to high learner achievement. Komarraju (2013), emphasises that learners' personality differences may influence their classification of a good teacher. There are no clear criteria in outlining characteristics for good teachers, as this may depend on how an individual learner views a good teacher. Despite this contention, authors such as Furnham and Chamorro-Premuzic (2005), emphasise that, in general, learners like open and agreeable teachers who are smart, emotionally adjusted and hard-working.

Good teachers have an open platform for communicating with learners in terms of subject content and learners' progress, motivating learners and praising them for good work. Good teachers create opportunities for learners to ask questions and entertain learners' questions to ensure that learners understand the content presented and are motivated to have interest in the subject. Good teachers are well known for treating their lesson presentations as a serious academic endeavour and as intellectually-demanding and as important as their coursework during their years of teacher training (Samples and Copeland, 2013). This implies that good teachers consider their teaching responsibility as a serious business and treat it with due respect, the same way they treated their professional training that made them to be good teachers. Hence, the professional training of teachers informs the teachers' own understanding and respect of their lesson content and presentation.

Good teachers are active constructivists of knowledge in their classroom. While teaching methods vary based on the situation and content, good teachers create critical thinking environments where learners learn by confronting each other's experience of the lesson situation with real life problems that will challenge them to generate new ideas, rethink their assumptions and examine their solutions (Samples and Copeland, 2013). This constructivist perspective of creating knowledge in the classroom as made possible by good teachers, believe that every learner has the ability to construct new knowledge once provided with opportunities.

As a result of constructivism, good teachers set high academic standards for learners and consistently challenge their learners to do their best and discover their potential. This type of interaction is important as it builds learners' confidence towards the teacher and also helps learners to establish and believe in their potential. This interaction helps learners to grasp new concepts, gain new insights about the unknown and strengthen their relationships with one another. This constructivism helps to generate new knowledge, thus a good teacher knows how to create an atmosphere conducive to the creation of new knowledge.

Not all teachers demonstrate the professional characteristics of a good teacher. Because of this difference in professional competencies amongst teachers, some learners attain higher achievements in some classes than others. Typical professional competencies relate to nurturing learners' potential, possessing a sound subject knowledge base, constant monitoring of learners' progress, impartiality, consistent lesson preparedness, a high level of intellectual competence and good communication skills (Adeosun et al., 2013; Vlad and Ciascai, 2014).

\subsection{Personality Characteristics}

While professional characteristics focus on the teachers' professional requirements and suitability for the teaching career, personality traits define a good teacher on the basis of a teacher's specific humane characteristics that cause an individual teacher to behave in certain ways, other than by professional knowledge or abilities (Gao and Liu, 2013). Personality refers to the patterns of behaviours that are unique to the individual and how these habits and behaviours are organised (Arif et al., 2012). Personality is therefore person-bound and differs from person to person and direct a person to behave in a unique way. The personality of the teacher influences classroom climate and has major implications regarding learners' motivation and attitude towards learning (Açıkgöz, 2005; Maurer, 2012).

The personality of the teacher is an important variable in shaping the teaching and learning processes (Arif et al., 2012). Personality shapes the behaviours of the teacher, as it is the interface between the teacher and the learners. Good teachers demonstrate a good personality during teaching which draws learners' attention even if the teacher does not mention a word. Any teacher whose personality creates a conducive learning environment in which learners feel confident and motivated to learn is characterised as having a good teaching personality (Sharma and Gupta, 2014).

All teachers have their own, unique sets of personal characteristics manifested by their behaviours towards others and how they react to those that respond to them (Arif et al., 2012). For example, teachers with dictatorial characteristics are likely to exhibit them during lesson presentation which then shapes negative interaction between teachers and learners. On the contrary, well-balanced and non-anxious teachers can create an active learning 
environment where learners are at ease to engage with the subject content. Therefore, teacher personality has a direct impact on learning and teaching in classrooms. It is significant for teachers to recognise their own personality type and the personality type of others in order to help establish a positive intra-personal and inter-personal relationship with each other in the work environment. This implies that personality recognition is critical in identifying and selecting suitable teaching staff.

Research has proved that personality recognition has been useful in forecasting workers' suitability to fill certain roles, establishing relationships in organisations and predicting future performance (Arif et al., 2012). Other research findings on personality recognition suggests that right personality characteristics can ensure good teachers entering the profession, retain teachers in the profession and attract teachers who will remain in teaching and be committed to learner achievement (Duckworth et al., 2009; Sharma and Gupta, 2014).

Positive affection and relaxed atmosphere are critical in ensuring optimal learning. If learners fear the teacher, optimal learning is inhibited. Studies conducted with learners on what makes a good teacher, revealed that good teachers are those teachers who are mentally healthy and nurturing, and enable learners to score maximum marks in the subjects taught by them (Cook-Sather, 2002; White, 2009). From learners' perspective, the personality of a good teacher can be manifested by learners' performance in the subject the teacher offers.

The personality of a good teacher yields good learner performance. Personal characteristics such as aggression and hostility cannot constitute a good teacher, because such characters suppress creativity and learners' curiosity. Learners who are exposed to unhealthy behavioural patterns of teachers, such as hostility and being over-critical and restrictive, usually have low achievement because of the learners' decreased interest in the subject (Arif et al., 2012). Therefore, the low achievement makes teachers with unhealthy personality patterns not to be regarded as good teachers.

There is ample evidence supporting the view that the personality of a teacher is a very important enabler of successful teaching and that teacher effectiveness is perceived to exist as a consequence of the characteristics of a teacher as a person (Arnon and Reichel, 2007; Thompson et al., 2004). The effective use of a teacher's personality is essential in conducting instructional activities. Learners learn from a teacher's personality even if there is no formal interaction between learners and teacher.

The teacher whose personality helps create and maintain the classroom as a learning environment in which learners feel comfortable and in which they are motivated to learn depicts a desirable teaching personality and is thus a good teacher (Arif et al., 2012). A competent teacher demonstrates a good combination of personality traits such as kindness, enthusiasm, friendliness, helpfulness and patience in performing the tasks (Arnon and Reichel, 2007; Murphy et al., 2004). A good teacher cares much about learners and communicates politely with them.

Despite the significance of personality recognition, there is lack of measures in Namibia to recognise whether students applying to teacher training institutions possess the necessary personality that will make them good teachers and remain in the profession. This results in students becoming teachers when they were not meant to be teachers by virtue of their personality. The unsuitability of students entering the teaching profession can be evident in their learners' poor performance and in their turnover (Bennell, 2004).

The fact that there are no reliable mechanisms to use in Namibia to determine the required personal characteristics for the teaching profession relate to aspects such as evaluating practising teachers to find out whether they have the right personal characteristics, has been based on preconceived notions of good teaching practice, rather than determining teacher personality as a true reflection of learner performance (Maurer, 2012).

Characteristics such as extraversion, social attractiveness and assertiveness have been found to elevate an individual's rating of teacher performance in the absence of any empirical evidence indicating good learner performance (Duckworth et al., 2009). This implies that there is lack of proper systems to detect the personal characteristics of a good teacher as current evaluation measures are dominated by subjectivity rather than objectivity of teacher effectiveness.

Even if students with personal characteristics relative to good teachers are detected while in training, there will still be inequity in terms of deployment. Graduating teachers are not randomly assigned to schools; instead, teachers choose the school where to work based on their preferences. Good teachers usually accept deployment in best performing districts, thereby creating a selection bias where the presence of teachers with the preferred teacher personality characteristics are concentrated in high performing schools at the expense of low performing schools (Duckworth et al., 2009).

The tendency of teachers opting for their own deployment is common in most sub-Saharan Africa countries including Namibia, where graduates choose their own duty station which led to some schools having good teachers and high learner performance compared to other schools, especially rural; (UNICEF Report, 2014). There is a lack of a deployment policy for qualified teachers among Namibian schools to solve inequitable distribution of qualified teachers among schools.

It becomes evident that there is a close correlation between the personality characteristics of a good teacher and learner performance. A good teacher reveals personal characteristics such as being kind, enthusiastic, friendly and helpful. A good teacher demonstrates well-balanced and non-anxious personal behaviours which stimulate a conducive learning environment where learners are at ease to engage with the subject content. This implies that professional qualification and experience alone cannot bring about optimal learning in schools.

\subsection{Social Characteristics}

Teachers do not operate in isolation as schools are organisations composed of different units as well as different people of different social backgrounds (Dittmar et al., 2002). In strengthening social characteristics of teachers, a 
school cluster system was introduced in Namibia as from 1996. A school cluster system relates to the grouping of schools that are geographically close together in order to share educational resources and instructional materials with the purpose of improving educational standards and promote social cohesion among schools (Dittmar et al., 2002; Giordano, 2008). The nature of the school as an organisation requires teachers to demonstrate certain social characteristics in the execution of their duties.

In the context of this study, social characteristics refer to the humane abilities to interact with all the people involved in their working environment. Among other stakeholders, teachers execute their work in close partnership with learners, parents, fellow teachers and school leaders. While interacting with these people, teachers should demonstrate exceptional skills of working with people.

Good teachers establish a good relationship with their learners, which Vlad and Ciascai (2014) define as the teacher's ability to function in a social group and take on the social responsibilities of a teacher pertaining to learners' social welfare. Good teachers are socially responsible, implying they treat learners equally, listen to and care about learners' problems and get to know each learner as an individual (Arnon and Reichel, 2007). A good relationship between teachers and learners leads to learners' motivation, good lesson engagement and high learner achievement (Hughes, 2011). A good relationship between the teacher and learners is essentially as in most cases learners are not really cared for. A teacher should be willing to fully execute his or her role of in loco parentis to all learners entrusted in their care. This interaction makes learners feel welcomed, needed and motivated to learn.

Many individuals entering the teaching profession indicate working with learners as one of the key reasons that got them attracted to the teaching profession (Sinclair, 2008). Good teachers develop positive relationships with their learners by engaging them in discussion, which then helps to bridge the gaps between teachers and learners. Good teachers are well-known for expressing how they cannot wait to get back to school or describing how fulfilling it is just to be with learners at school (Cornu, 2013). Being passionate about learners is representative of a positive relationship established between the teacher and the learners, representing social characteristics of a good teacher.

This positive relationship emanates from the satisfaction teacher draws from their learners as a result of their frequent engagement with them. This engagement can be in the form of lesson presentation, field trips and the positive feedback exchanged between teachers and learners (Robert et al., 2012). Good teachers do not only facilitate learning the subject, but their teaching also seeks to establish a positive and beneficial working learning relationship with their learners, thus enhancing learner performance.

The positive relationship between teachers and learners has a significant influence on how teachers feel and act on daily basis as teachers' relationships with their learners shape teachers' state of mind in terms of whether they feel good or bad (Cornu, 2013; Kitching et al., 2009). The relationship between the teacher and the learners also determines the learners' state of mind and their success (Robert et al., 2012). A positive relationship between teachers and learners encourages a classroom climate that helps learners to continuously engage with teachers (Robert et al., 2012). Apart from learners, good teachers have positive interaction with fellow teachers.

A strong, positive working relationship between teachers themselves is critical in ensuring a sense of belongingness and social connectedness (Cornu, 2013). Good teachers do not experience isolation and neglect at work because they recognise fellow teachers and know how to develop relationships with fellow teachers who can provide them with the support they need. Good teachers express how they would not be able to work confidently if they did not have the people around them on whom they can rely or just talk to each day and share laughter (Cornu, 2013).

This social characteristic with regard to supporting one another and recognising the value of others in the surrounding promotes the social ideals of the Hierarchy of Needs theory as advanced by Abraham Maslow, as well as the Existence, Relatedness and Growth theory of Claydon Alderfer, both of which theories emphasise a need for an individual to belong and relate to others in a social setting. These positive working relationships are essential for establishing friendship between teachers which is beneficial on both the academic and social front.

Jordan (2006), maintains that social connections among teachers are vital in promoting creativity, unity and empowerment among themselves. A good teacher shows passion towards others and shares wisdom on how to manage and take control of situations. Good teachers value the time they spend together to explore solutions to problems, as they have the ability to talk about teaching and learning and interact in a professional way. According to TRACES (2012), good teachers are considerate of others' input by receiving support from others who are going through a similar social and academic experience.

A good teacher therefore has the ability to recognise the presence of other teachers and appreciate their presence by engaging with them in their duties. This ensures that the social needs of teachers such as to associate with each other is catered for. Association ensures collegiality such that teachers do not feel isolated or neglected, which negatively affects their self-esteem and performance level, resulting in low learner achievement and high teacher attrition (Bennell, 2004).

Part of positive association is the relationship between teachers and their school leaders. Teachers work under the guidance of school principals and heads of departments. These leaders provide guidance and supervision to teachers in order to perform their duties effectively. A good teacher plays a role in establishing and maintaining a working relationship with the supervisors (Abiddin, 2006). Good teachers attend to instructions and carry them out diligently without having to be forced to execute their work or failing to meet deadlines. Failing to execute duties and not meeting deadlines results in decreased social connections, poor teacher performance and ultimately poor learner performance.

In addition to professional and personal characteristics, it is clear that a good teacher possesses social characteristics enabling him or her to function effectively in the working environment. Social characteristics of a 
good teacher include establishing positive relationships with learners in order to promote teacher-learner connectedness, recognising the presence of other teachers and making use of their inputs by actively interacting with each other and by attending to instructions to carry out a mandate as requested by supervisors.

\section{Conclusion}

There is substantive evidence that a good teacher is constituted by a blend of diverse characteristics, which relates to professional, personal and social characteristics. Teachers' blend of characteristics contribute significantly to the quality of teaching and learning processes. To realise good teaching and good learning, it is imperative that teachers with the correct blend of characteristics for good teaching are appointed in order to rescue rural schools from deteriorating teacher shortages and poor learner performance. However, the challenge is likely to persist on identifying suitable students for teacher training, as well as deployment upon completion of teacher training.

Despite this foreseen challenge, a proper understanding of what constitute a good teacher as outlined in this article, is essential in enabling educational authorities to plan better on how the selection of potential student teachers and subsequent teachers can be done. This may include administering standard entry tests to prospective students, covering aspects relating to professional, personal and social dimensions of a good teacher. Such selection may help to ensure that those entering the teaching career are those who are indeed destined to be teachers during a particular time of their lifetime, and effect good teaching for good learning.

\section{Reference}

Abiddin, N. Z. (2006). Mentoring and coaching: The roles and practices. The Journal of Human Resource and Adult Learning, 1: 107-16. Available: http://www.hraljournal.com/Page/15Norhasni\%20Zainal\%20Abiddin.pdf

Açıkgöz, F. (2005). A study on teacher characteristics and their effects on students' attitudes. The Reading Matrix, 5(2): 103-15.

Adedeji, S. O. and Olaniyan, O. (2011). Improving the conditions of teachers and teaching in rural schools across African countries. UNESCO: Addis Ababa.

Adeosun, O., Oni, S. and Oladipo, B. (2013). Affective and cognitive characteristics of Nigerian student-teachers: Towards developing an effective teacher education framework. Journal of International Cooperation in Education, 15(3): 39-58.

Anney, V. C. (2014). Ensuring the quality of the findings of qualitative research: Looking at trustworthiness criteria. Journal of Emerging Trends in Educational Research and Policy Studies (JETERAPS), 5(2): 272-81.

Arif, M. I., Rashid, A., Tahira, S. S. and Akhter, M. (2012). Personality and teaching: An investigation into prospective teachers' personality. International Journal of Humanities and Social Science, 2(17): 161-71.

Arnon, S. and Reichel, N. (2007). Who is the idea teacher? Am I? Similarity and difference in perception of students of education regarding qualities of a good teacher and of their own qualities as teachers. Teachers and Teaching: Theory and Practice, 13(5): 441-64.

Ary, D., Jacob, L. C., Sorensen, C. and Razavieh, A. (2010). Introduction to research in education. Wadsworth: Belmont, CA.

Atieno, O. P. (2009). An analysis of the strengths and limitation of qualitative and quantitative research paradigms. Problems of Education in the 21st Century, 13: 13-18. Available: http://www.scientiasocialis.lt/pec/files/pdf/Atieno_Vol.13.pdf

Barley, Z. A. and Beesley, A. D. (2007). Rural school success: What can we learn? Journal of Research in Rural Education, 22(1): 1-16.

Bennell, P. (2004). Teacher motivation in sub-Saharan Africa and south Asia. Education papers. Available: http://www.eldis.org/fulltext/dfidtea.pdf

Bullock, M. (2015). What makes a good teacher? Exploring student and teacher beliefs on good teaching. Rising Tide, 7: 1-30.

Burnett, G. and Lingam, G. I. (2007). Reflective teachers and teacher educators in the Pacific region: Conversations with us not about us. Review of Education, 53(3): 303-21.

Campbell, R. J., Kyriakides, L., Muijsc, R. D. and Robinsona, W. (2004). Effective teaching and values: Some implications for research and teacher appraisal. Oxford Review of Education, 30(4): 451-65.

Chiromo, A. S. (2009). Research methods and statistics: A students' guide. Midlands State University: Gweru.

Choy, L. T. (2014). The strengths and weaknesses of research methodology: Comparison and complimentary between qualitative and quantitative approaches. IOSR Journal of Humanities and Social Science (IOSRJHSS), 19(4): 99-104.

Cook-Sather, A. (2002). Re(in)forming the conversations: Student position, power and voice in teacher education. The Radical Teacher, 64: 21-28. Available: https://www.jstor.org/stable/pdf/20710155.pdf?seq=1\#page_scan_tab_contents

Cornu, R. E. (2013). Building early career teacher resilience: The role of relationships. Australian Journal of Teacher Education, 38(4): 1-16.

Creswell, J. W. (2014). Educational research: Planning, conducting and evaluating quantitative and qualitative research. Pearson Education Limited: California.

Devine, D., Fahie, D. and McGillicuddy, D. (2013). What is 'good' teaching? Teacher beliefs and practices about their teaching. Irish Educational Studies, 32(1): 83-108. 
Dewar, K. (2002). On being a good teacher. Journal of Hospitality, Leisure, Sport and Tourism Education, 1(1): 6167.

Dittmar, F., Mendelsohn, J. and Ward, V. (2002). The cluster system in Namibia. RAISON: Windhoek.

Duarte, F. P. (2013). Conceptions of good teaching by good teachers: Case studies from an Australian university. Journal of University Teaching and Learning Practice, 10(1): 1-15.

Duckworth, A. L., Quinn, P. D. and Seligman, M. P. (2009). Positive predictors of teacher effectiveness. Journal of Positive Psychology, 4(6): 540-47.

Dudwick, N., Kuehnast, K., Jones, V. N. and Woolcock, M. (2006). Analysing social capital in context: A guide to using qualitative methods and data. World Bank Institute: Washington.

Espina, M. R. (2013). Instrument development: Defining the ideal and assessed college teacher. GSE Journal of Education, 12: 110-24.

Furnham, A. and Chamorro-Premuzic, T. (2005). Individual differences in students' preferences for lecturers' personalities. Journal of Individual Differences, 26(4): 176-84.

Gao, M. and Liu, Q. (2013). Personality traits of effective teachers represented in the narratives of American and Chinese preservice teachers: A Cross-cultural comparison. International Journal of Humanities and Social Science, 3(2): 84-95.

Giordano, E. A. (2008). School cluster and teacher resources centres. UNESCO: Paris.

Guba, E. G. (1981). Criteria for assessing the trustworthiness of naturalistic inquiries. Educational Communication and Technology Journal, 29(2): 75-91.

Heeralal, P. J. H. (2014). Preparing pre-service teachers to teach in rural schools. Mediterranean Journal of Social Sciences, 5(20): 1795-99.

Hughes, J. (2011). Longitudinal effects of teacher and student perceptions of teacher student relationship qualities on academic adjustment. The Elementary School Journal, 112(1): 38-60.

Inan, B. (2014). A Cross-cultural understanding of the characteristics of a good teacher. Anthropologist, 18(2): 42732.

Johnson, B. R. and Onwuegbuzie, A. J. (2004). Mixed methods research: A research paradigm whose time has come. Educational Researcher, 33(7): 14-26.

Jordan, J. (2006). Relational resilience in girls in goldstein. In Goldstein, S. and Brooks, R. (Eds.). Handbook of resilience in children. Plenum Publishers: New York. 79-90.

Kahn, V. J. and Best, J. W. (2006). Research in education. 10th edn: Pearson Education: Boston.

Khojastehmehr, R. and Takrimi, A. (2009). Characteristics of effective teachers: Perceptions of the English teachers. Journal of Education and Psychology, 3(2): 53-66.

Kitching, K., Morgan, M. and O'Leary, M. (2009). It's the little things: Exploring the importance of commonplace events for ECTs' motivation. Teachers and Teaching: Theory and Practice, 15(1): 43-58.

Komarraju, M. (2013). Ideal teacher behaviours: Student motivation and self-efficacy predict preferences. Teaching of Psychology, 40(2): 104-10.

Lasley, I. I. T. J., Siedentop, D. and Yinger, R. (2006). A systemic approach to enhancing teacher quality: The ohio model. Journal of Teacher Education, 57(1): 13-21.

Leedy, P. D. and Omrod, J. E. (2005). Practical research: Planning and design. 8th edn: Prentice Hall: New Jersey.

Littkey, D. (2004). The big picture: Education is everyone's business. Association for Supervision and Curriculum Development: Alexandria VA.

Markley, T. (2004). Defining the effective teacher: Current arguments in education. Essays in Education, 11(3): 114.

Maurer, A. B. (2012). The Impact of positive traits on teacher performance within a systems driven charter school management organisation. Unpublished Thesis. Philadelphia: University of Pennsylvania.

Mitra, S., Dangwal, R. and Thadani, L. (2008). Effects of remoteness on the quality of education: A case study from North Indian schools. Australasian Journal of Educational Technology, 24(2): 168-80.

Mullock, B. (2003). What makes a good teacher? The perceptions of postgraduate TESOL students. Prospect, 18(3): 3-24.

Murphy, P. K., Delli, L. A. M. and Edwards, M. N. (2004). The good teacher and good teaching: Comparing beliefs of second-grade students, pre-service teachers and in-service teachers. The Journal of Experimental Education, 72(2): 69-92.

Okoro, C. O. and Chukwudi, E. K. (2011). The ideal teacher and the motivated student in a changing environment. Journal of Educational and Social Research, 1(3): 107-12.

Rivkin, S. G., Hanushek, E. A. and Kain, J. (2005). Teachers, schools and academic achievement. Econometrica, 73(2): 417-58.

Robert, C. P., Bridget, K. H. and Joseph, P. A. (2012). Teacher-student relationships and engagement: Conceptualising, measuring and improving the capacity of classroom interactions. In Christenson, S.L. Reschly, A.L. and Wylie, C. (Eds.). Handbook of research on student engagement. University of Virginia: Charlottesville. 365.

Rockoff, J. E. (2004). The impact of individual teachers on student achievement: Evidence from panel data. American Economic Review, 94(2): 247-52.

Samples, J. W. and Copeland, S. E. (2013). The universality of good teaching: A study of descriptors across disciplines. International Journal of Teaching and Learning in Higher Education, 25(2): 176-88. 
Sharma, D. and Gupta, K. (2014). Values and personality traits of aided and self- finance teacher-educators. An International Journal of Education and Applied Social Sciences, 5(3): 201-10.

Shishavan, H. B. (2009). Characteristics of an effective English language teacher as perceived by Iranian teachers and learners of English. English Language Teaching, 2(4): 130-24.

Simons, H. (2009). Case study research in practice. Sage Publications: London.

Sinclair, C. (2008). Attracting, training and retaining high quality teachers: The effect of initial teacher education in enhancing student teacher motivation, achievement and retention. In McInerney, D.M. and Liem, A.D. (Eds.). Teaching and learning: International best practice. Information Age Publishing: Charlotte North Carolina. 133-67.

Thompson, S., Greer, J. G. and Greer, B. B. (2004). Highly qualified for successful teaching: Characteristics every teacher should possess. Available: http://www.usca.edu/essays/vol102004/thompson.pdf

TRACES, 2012. "Cooperation among teachers." In Paper Presented at the TRACES Conference, 9-12 April 2012, Naples, Italy.

UNICEF Report (2014). The impact of incentives for the recruitment and retention of qualified teachers in Namibia's remote schools. University of Stellenbosch: Cape Town.

Vlad, I. E. and Ciascai, L. (2014). Students' perception of the personal characteristics of ideal teacher: A pilot study. Acta Didactica Napocensia, 7(2): 41-48.

Walker, R. J. (2008). Twelve characteristics of an effective teacher. Educational Horizons, 87(1): 61-88.

White, B. (2009). Student perceptions of what http://atea.edu.au/ConfPapers/2009/Refereed/BWhite.pdf

makes good teaching.

Available: 